$\underline{\text { Review Article }}$

\title{
NERIUM OLEANDER: IT'S APPLICATION IN BASIC AND APPLIED SCIENCE: A REVIEW
}

\author{
1SAABIYA FAROOQUI, ${ }^{2}$ TULIKA TYAGI
}

1P.G. Department of Zoology, Ranchi University, Ranchi-834002 Jharkhand India. 'Department of Botany, University of Rajasthan, JLN Marg, Jaipur-302004 Rajasthan India

Email: farooqui.saabiya@gmail.com, tulikatyagi_062@yahoo.co.in

Received: 11 Sep 2017 Revised and Accepted: 22 Jan 2018

\begin{abstract}
Nerium oleander is an important medicinal plant in Indian folk medicine. It is a potentially lethal plant in many cases and poisoning is reported in tropical and subtropical parts of the world as well as a number of suicidal cases are also prevalent in South Asian countries, especially in India and Sri Lanka. All parts of the plant are toxic and contain a variety of cardiac glycosides which includes neriin, oleandrin, cardenolides, gentiobiosyl and odoroside. This plant species also produce secondary metabolites such as alkaloids, flavonoids and steroids which have pharmacological applications. The important pharmacological activities are antibacterial, anthelmintic, anti-inflammatory, hepatoprotective, immunopotential, antipyretic, antioxidant, antifungal, anticancer and anti-HIV activity. This review describes the evidence-based information regarding pharmacological activity as well as phytochemicals of this plant.
\end{abstract}

Keywords: Nerium oleander, Antibacterial, Pharmacological, Anthelmintic, Antioxidant

(C) 2018 The Authors. Published by Innovare Academic Sciences Pvt Ltd. This is an open access article under the CC BY license (http://creativecommons.org/licenses/by/4.0/) DOI: http://dx.doi.org/10.22159/ijpps.2018v10i3.22505

\section{INTRODUCTION}

Nerium oleander is an evergreen shrub in the dogbane family Apocynaceae (fig. 1). It is the only species currently classified in the genus Nerium. It is commonly known as oleander, from its superficial resemblance to the unrelated olive Olea. It is widely cultivated and though to be originated from Southwest Asia. Oleander grows well in warm subtropical regions, where it is extensively used as an ornamental plant in landscapes, in parks, and along roadsides. The oleander is most prevalent, and its alluring flowers make it a particular hazard for accidental ingestion [1]. The plant also has shown the toxicologic importance for accidents when used in folk medicines, in homicides or suicides [2]. All parts of the oleander plant contain cardiac glycosides, including the roots and the smoke produced from burning, as heat does not inactivate the glycosides. This plant is known by many names throughout the world which includes Adelfa, Baladre, Cascabela thevetia, Cerbera thevetia, Common Oleander, Exile Tree, Huang Hua Jia, Jia Zhu Tao, Kaner, Karvir, Karvira, Laurel Rosa, Laurier-Rose, Laurier Rose, Laurose, Nérier à Feuilles de Laurier, Nérion, Nerium indicum, Nerium Oleander, Nerium odorum, Oleander blatter, Oleandre, Oleandri folium, Rose Bay, Rose Laurel, Sweet Scented Oleander, Thevetia neriifolia, Thevetia peruviana, Yellow Oleander.

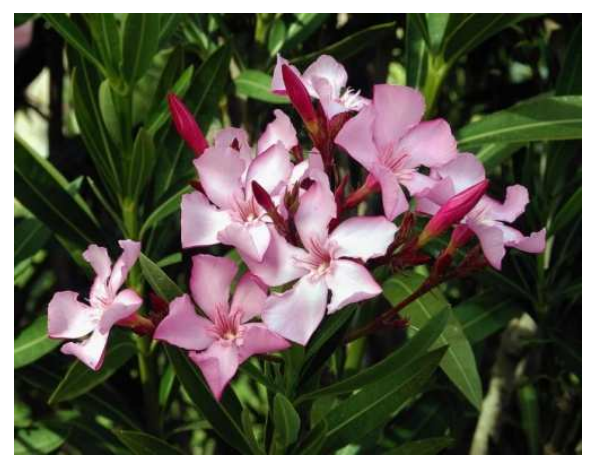

Fig. 1: Nerium oleander L. plant in a flowering condition

Nerium oleander has historically been considered a poisonous plant because some of its compounds exhibit toxic effect, especially to animals, when consumed in high amounts. Ingestion of this plant can affect the gastrointestinal system, the heart, and the central nervous system. Some invertebrates are known to be unaffected by oleander toxins and feed on the plants. Caterpillars of the polka-dot wasp moth (Syntomeida epilais) feed specifically on oleanders and survive by eating only the pulp surrounding the leaf-veins, avoiding the fibres. Larvae of the common crow butterfly (Euploea core) also feed on oleanders, and they retain or modify toxins, making them unpalatable to would-be predators such as birds, but not to other invertebrates such as spiders and wasps. Despite the danger, oleander is of great medicinal importance and used for heart conditions, asthma, epilepsy, cancer, painful menstrual periods, leprosy, malaria, ringworm, indigestion, and venereal disease; and to cause abortions, as well as drugs derived from this plant, is used in treatment of cancer and the research is ongoing for its future implementation.

\section{Chemical constituents}

The plant contains a number of related cardiac glycosides similar in activity to digitalis [3]. The main glycosides are oleandrin, neriine, Cardenolides, gentiobiosyl, oleandrin and odoroside are also present [4]. In addition, a variety of other pharmacologically active compounds, including folinerin, rosagenin, rutin and oleandomycin have been identified in the plant.

In leaves, two new cardenolides, 3 beta-0-(D-2-0-methyldigitalosyl)-14 beta-hydroxy-5 beta-Carda-16,20 (22)-dienolide (1) and 3 beta-hydroxy-8,14-epoxy-5 beta-Carda-16,20 (22)-dienolide (2), and two known cardenolides, 3 beta-O-(D-digitalosyl)-14 betahydroxy-16 beta-acetoxy-5 beta-card-20 (22)-enolide (3) and 3 beta-0-(D-digitalosyl)-14 beta-hydroxy-5 beta-card-20 (22)-enolide (4), have been isolated [5].

Four CNS depressant cardenolides including a new cardenolide, neridiginoside and three known constituents, nerizoside, neritaloside and odoroside-H, have been isolated which showed CNS antidepressant activity. The structure of neridiginoside was elucidated as 3 beta-0-(D-diginosyl)-5 beta, 14 beta-dihydroxy-card-20 (22)enolide [6]. A polysaccharide fraction, NIB-2, was obtained from the $3 \%$ aqueous sodium carbonate extract which was composed of rhamnose, arabinose, galactose, in the ratios of 1.0:10.4:4.4, along with $4 \%$ of galacturonic acid. Further analysis showed that it mainly contained arabinogalactan having a backbone of 1,6-linked beta-Galp, with branches at 0-3, consisting of a terminal, 1,5-, and 1,3,5-linked arabino furanosyl residues, and a small proportion of galactosyl 
residues at the termini. New ursane-type triterpene 1, oleanane-type triterpene 2, and dammarane-type triterpene 15 were isolated from the leaves of Nerium oleander together with 12 known triterpenes, 3beta-hydroxy-12-ursen-28-oic acid (ursolic acid,3beta,27-dihydroxy12-ursen-28-oic acid, 3beta,13beta-dihydroxyurs-11-en-28-oic acid, 3beta-hydroxyurs-12-en-28-aldehyde, 28-norurs-12-en-3beta-ol, urs12-en-3beta-ol, urs-12-ene-3beta,28-diol, 3beta-hydroxy-12-oleanen28-oic acid (oleanolic acid), 3beta,27-dihydroxy-12-oleanen-28-oic acid, 3beta-hydroxy-20(29)-lupen-28-oic acid (betulinic acid, 20(29)lupene-3beta,28-diol (betulin, and (20S,24R)-epoxydammarane3beta,25-diol [7].

Two new taraxasterane-type triterpenes, 20beta,28-epoxy-28 alphamethoxytaraxasteran-3beta-ol and 20 beta, 28-epoxytaraxaster-21en-3beta-ol, were isolated from an ethyl acetate extract of the leaves of Nerium oleander, together with ursane-type triterpenes, 28-norUrs-12-ENE-3beta,17beta-diol and 3beta-hydroxyurs-12-en-28aldehyde [8]. Hot-water extract of $N$. Indicum leaves yielded 3-0caffeoylquinic acid (chlorogenic acid) and its structural isomer, 5-0caffeoylquinic acid. Both compounds were shown to inhibit alphaglucosidases in a non-competitive manner and thus were antihyperglycemias [9].

Three nematocidal cardenolides were obtained from the AcOEt extract of Nerium indicum Mill. By bioassay-guided fractionation. They include a new compound, 3 beta-O-(beta-D-diginosyl)-14, 15alphadihydroxy-5alpha-card-20(22)-enolide, and two known compounds, uzarigenin and cardenolide $\mathrm{N}-1$ [10]. Two new cardenolide monoglycerides, cardenolides B-1 and B-2 were isolated from Nerium oleander, together with oleagenin which is the first isolated compound from natural sources. The structure of compounds were established on the basis of their spectroscopic data [11].

\section{Ethnomedicinal value}

A decoction of the leaves has been applied externally in the treatment of scabies and to reduce swellings. Bark is bitter and is used as cathartic, febrifuge and intermittent fever. Oil prepared from the root bark is used in the treatment of leprosy and skin diseases of a scaly nature. Seeds are used as a purgative in dropsy and rheumatism. The root is powerful resolvable and is used in the form of plasters and is applied to tumours because of its poisonous nature it is only used externally. The leaves and the flowers of Nerium are cardiotonic, diaphoretic, and diuretic, anticancer, antibacterial. Nerium is beaten into a paste with water and applied to lesion and ulcers on the penis. The whole plant has anticancer properties and its use in the treatment of cancer and found that the flowers, leaves, leaf juice or latex, bark and roots have been used against corns, warts, cancerous ulcers, carcinoma, ulcerating or hard tumours [12].

In 2011, the Federal Drug Administration (FDA) concluded the first trial phase of oleander extract and found it to be safe for use in the treatment of cancer. It is also found that Bladder, colorectal, breast, pancreatic and appendiceal cancers responded favourably to the extract with very little adverse reaction or cardiotoxicity. Anvirze is an aqueous extract of the plant Nerium oleander which has been utilized to treat patients with advanced malignancies [13, 14]. Other medicinal uses of Nerium oleander include treating ulcers, haemorrhoids, leprosy, to treat ringworm, herpes, and abscesses.

\section{Biological activities}

\section{Antioxidant activity}

The total level of antioxidant activity was higher in Crude Nerium oleander leaves extract (72.8\%), as compared to flower (68\%) and Superoxide radical whereas scavenging activity was higher in Crude flower extract (66\%) as compared to leaves $25 \%$. Nerium oleander possesses an effective antioxidant activity, which includes free radical scavenging and reducing power and the antioxidant activity was correlated with the amount of the total phenolic content present in the respective extracts in each assay [15]. The leaf, stem and root extracts of $N$. Oleander is an effective free radical scavenger and might be used as a natural source of potent antioxidant.

\section{Anti-inflammatory activity}

The ethanolic extracts of Nerium oleander dried leaves and fresh flowers exhibited potent anti-inflammatory activity against carrageenan-induced hind paw edema model in mice without inducing any gastric damage.

\section{Antimicrobial activity}

The plant has provided a source of inspiration for novel drug compounds, as plants derived medicines have made significant contributions towards human health. The effect of ethanolic leaf extract was significant on bacterial strains such as B. Subtilis and Nyctanthes arbortristis. The antibacterial activity of oleander extracts on gram-negative bacteria and concluded that antibacterial activity was found due to phenolic compounds that decrease the concentration of radicals.

\section{Larvicidal activity}

The aqueous leaf extract of Nerium oleander was exhibited ovicidal and larvicidal properties [16] and for the ovicidal and adulticidal activity of this plant against Anopheles stephensi was also recorded [17]. Culex quinquefasciatus larval mortality was tested against Nerium oleander crude hexane and aqueous flower extracts [18].

\section{Anticancer activity}

Ali and co-workers [19] was able to extract essential oil from the flowers of the oleander. It showed antitumor activity on the cell lines, Ehrlich Ascites Carcinoma (EAC). Different amount of Anvirzel (1.0 ng. ml- 1 to 500 micrograms. ml-1) or Oleandrin (0.01 ng. ml-1 to 50 micrograms. ml-1) in both continuously treated and pulsetreated/recovery Cell cultures [20]. Both Oleandrin and Anvirzel were able to induce cell killing in human cancer cells, but not in murine cancer cells.

\section{Cellular and humoral immune responses}

Concurrent research has identified very positive immunestimulating properties of the Nerium oleander plant. Research has confirmed that Nerium extracts have been shown to stimulate the immune system by stimulation of the function and capability of specific subsets of mononuclear cells and specifically stimulates $\mathrm{T}$ and B lymphocytes, the cell-mediated and the humoral mediated immune systems. Nerium oleander has marked immunomodulatory effect on the rabbit immune system. Treatment with a dose of 75 $\mathrm{mg} / \mathrm{kg}$ body weight of a leaf extract in rabbits diminish the production of antibodies and also exerted and inhibition of the delay hypersensitivity reaction and phagocytic activity, whereas treatment with low dose 50 and $25 \mathrm{mg} / \mathrm{kg}$ body weight subcutaneously caused stimulation of the immune system.

\section{Toxicity}

Nerium oleander has historically been considered a poisonous plant based on a number of its compounds that may exhibit toxicity, especially to animals, when consumed in high amounts. The entire oleander plant contains toxic cardiac glycosides. The highest levels are found in the roots and seeds. Even smoke from the plant and water in which the plant has been immersed can be toxic. Among these compounds are oleandrin and oleandrigenin, known as "cardiac glycosides" which are known to have a narrow therapeutic index and are toxic when ingested. Symptoms of oleander toxicity include pain in the oral cavity, nausea, emesis, abdominal pain, cramping, and diarrhoea.

In birds, there is a little 0.12 to $0.7 \mathrm{~g}$ of the plant has caused death [21]. Toxicity studies conducted [22] on animals concluded that the rodents were observed to be relatively insensitive to oleander "cardioactive glycosides" whereas other mammals, such as dogs and humans, are relatively sensitive to the effects of cardiac glycosides $[23,24]$. The death of a woman who self-administered "an undefined oleander extract" both orally and rectally and her oleandrin tissue levels were in the high range of reported levels at autopsy [25]. The death of a woman who ingested oleander 'tea' [26]. The cardiac glycosides may induce conduction defects among which most common were defects affecting the sinus or AV nodes with PR 
interval prolongation and progression to atrioventricular dissociation and systemic hyperkalemia induced by the plant may worsen cardiac function [27].

\section{Preventive measures}

Poisoning and reactions to oleander plants are evident quickly, requiring immediate medical care in suspected or known poisonings of both humans and animals. The activated charcoal may be administered orally and the conduction defects can usually be managed with atropine and isoproterenol [28]. Anti-digoxin Fab fragments have been shown to be a safe and effective treatment for serious cardiac arrhythmias induced by yellow oleander. Administration of anti-digoxin antibodies can restore sinus rhythm and rapidly correct bradycardia and hyperkalemia. However, the lower affinity of digoxin-specific Fab for nondigoxin cardiac glycosides in oleander results in a larger dose requirement than for usual digoxin toxicity.

\section{Nerium oleander in applied science}

Nerium oleander (containing oleandrin and other cardiac glycosides) was administered orally to 46 cancer patients where doses explored included those from $0.2 \mathrm{mg}$ to $10.2 \mathrm{mg}$ extract/day. These doses were administered daily in cycles consisting of 21 out of every $28 \mathrm{~d}$. The researchers concluded that PBI-05204 was "well tolerated up to the $10.2 \mathrm{mg}$ extract/day dosage" with few significant side effects and with evidence of tumor response. There does not appear to be any toxicity associated with exposure of a Nerium oleander extract to the skin. Both animals [29] and human [30] studies suggest that dermal application of Nerium oleander extract is safe indicating that these compounds are not readily absorbed through the skin. This clearly indicates that the extracts of this plant can be safely used not only for controlling pests but also can improve the immunity system of the insects of interest at a lower dose.

The unique properties of Nerium oleander also provide a remarkable age-defying result when applied to the skin. This finding led to the formation of Nerium International and the creation of the Nerium AD skin care line. Nerium scientists developed a breakthrough process, NBio-PL2, to derive an extract from the Nerium oleander plant in a way that preserves its unique and beneficial properties. This patented extraction process yields the NAE-8 extract, with powerful antioxidant properties, used to formulate the first-of-its-kind, agedefying Nerium product line.

The National Cancer Institute has defined oleandrin, one of the principal glycosides in Nerium oleander as "A lipid-soluble cardiac glycoside with potential antineoplastic activity". Cancer research at The University of Texas has demonstrated that components of Anvirzel $^{\mathrm{TM}}$ are active on dual pathways at the cellular level to promote apoptosis and/or autophagy (cell death) in human tumors, but not normal cells and blocks activation of a potent signal (NF-kB) that leads to tumor cell proliferation and metastases.

\section{Future application of Nerium oleander}

Utilizing biotechnology research and new breakthrough extraction technology, Nerium is continuing to develop a complete line of products that harnesses Nerium oleander's unique and effective properties. Anti-aging skin creams are abundant in today's cosmetic marketplace. Future product development includes Nerium AD Eye Cream Spot Cream, Skin Repair Cream, Blemish Cream and lots of such products. According to the American Cancer Society, "even a small amount of oleander can cause death", and "the effectiveness of oleander has not been proven". Nerium is also effective in increasing the CD4 counts of HIV-positive individuals with initial CD4 counts of less than 400 in a meaningful way over a 60 -day period. Nerium oleander aqueous extract as a novel anti-HIV therapeutic. This oleander is useful in future cancer and AIDS treatment [31]. Nerium as environmentally safer and greener approach for mosquito control and other pest control measure in the future [17].

\section{CONCLUSION}

From the review of the existing work it was concluded that $N$. oleander has been used in the treatment of various diseases and shows anticancer and antitumor properties as well as acts as a novel anti-HIV therapeutic. In recent years, ethnobotanical and traditional uses of natural compounds, especially of plant origin received much attention as they are well tested for their efficacy and generally believed to be safe for human use. It is the best classical approach in the search of new molecules for management of various diseases. Various bioactive compounds isolated from different parts of this plants. So, it is an utmost of importance to explore its potential in the field of medicinal and pharmaceutical sciences for novel application. As $N$. oleander is a popular remedy among the various ethnic groups, this plant is used in Ayurvedic and traditional medicine. So further or more work is needed to investigate the therapeutic potential of this plant.

\section{ACKNOWLEDGEMENT}

The authors would like to extend our gratitude to share their knowledge on the use of herbal medicinal plants as pharmacological important. Both the authors had contributed equally to the review work.

\section{AUTHOR CONTRIBUTION}

Both the authors had contributed equally to the review work.

\section{CONFLICTS OF INTERESTS}

All authors have none to declare

\section{REFERENCES}

1. Ansford AJ, Morris H. Fatal oleander poisoning. Med J Aust 1981;1:360-1.

2. Osterloh J, Herold S, Pond S. Oleander interference in the digoxin radioimmunoassay in a fatal ingestion. JAMA 1982;247:1596-7.

3. Radford DJ, Gillies AD, Hinds JA, Duffy P. Naturally occurring cardiac glycosides. Med J Aust 1986;144:540-4.

4. Duke JA. Handbook of medicinal herbs. Boca Raton, FL: CRC Press; 1985.

5. Siddiqui BS, Sultana R, Begum S, Zia A, Suria A. Cardenolides from the methanolic extract of Nerium oleander leaves possessing central nervous system depressant activity in mice. J Nat Prod 1997;60:540-4.

6. Begum S, Siddiqui BS, Sultana R, Zia A, Suria A. Bio-active cardenolides from the leaves of Nerium oleander. Phytochemistry 1999;50:435-8.

7. Dong $Q$, Fang JN. Structural elucidation of a new arabinogalactan from the leaves of Nerium indicum. Carbohydr Res 2000;332:109-14.

8. Zhao M, Zhang S, Fu L, Li N, Bai J, Sakai J, et al. Taraxasteraneand ursane-type triterpenes from Nerium oleander and their biological activities. Nat Prod 2006;69:1164-7.

9. Ishikawa $A$, Yamashita $H$, Hiemori $M$, Inagaki E, Kimoto $M$, Okamoto M, et al. Characterization of inhibitors of postprandial hyperglycemia from the leaves of Nerium indicum. J Nutr Sci Vitaminol (Tokyo) 2007;53:166-73.

10. Wang XB, Li GH, Zheng LJ, Ji KY, Lu H, Liu FF, et al. Nematicidal cardenolides from Nerium indicum. Mill-Chem Biodivers 2009;6:431-6.

11. Bai L, Wang L, Zhao M, Toki A, Hasegawa T, Ogura H, et al. Sterols with antileishmanial activity isolated from the roots of Pentalinon andrieuxii. J Nat Prod 2007;70:14-28.

12. Valnet J. Oleandro, Fitoterapia-cura delle malattie con lepiante. (Oleander, phytotherapy-diseases cure with plants). Aldo Martello-Giunti, Firenze, Italy; 1976. p. 332-3.

13. Pathak S, Multani AS, Narayan S, Kumar V, Newman RA. Anvirzel, an extract of Nerium oleander, induces cell death in human but not murine cancer cells. Anticancer Drugs 2000;11:455-63.

14. Manna SK, Sah NK, Newman RA, Cisneros A, Aggarwal BB. Oleandrin suppresses activation of nuclear transcription factor-kappaB, activator protein-1, and c-Jun NH2-terminal kinase. Cancer Res 2000;60:3838-47.

15. Iran MM. Antioxidant activity and total phenolic content of Nerium oleander L. grown in North of Iran. J Pharm Res Autumn 2012;11:1121-6. 
16. Kumar G, Karthik L, Rao KVB, Kirthi AV, Rahuman AA. Phytochemical composition and mosquito controlling property of Nerium oleander leaves (Apocynaceae) against Culex tritaeniorhynchus and Culex gelidus (Diptera: Culicidae). Asian Pacific J Trop Biomed 2012;2:1-6.

17. Roni M, Murugan K, Panneerselvam C, Subramaniam J, Hwang JS. Evaluation of leaf aqueous extract and synthesized silver nanoparticles using Nerium oleander against Anopheles stephensi (Diptera: Culicidae). Parasitol Res 2013;112:981-90.

18. Raveen R, Kamakshi KT, Deepa M, Arivoli S, Tennyson S. Larvicidal activity of Nerium oleander L. (Apocynaceae) flower extracts against Culex quinquefasciatus Say (Diptera: Culicidae). Int J Mosquito Res 2014;1:38-42.

19. Ali HFM, El-Ella FMA, Nasr NF. Screening of chemical analysis, antioxidant antimicrobial and antitumor activities of essential oil of oleander (Nerium oleander) flower. Int J Biol Chem 2009;4:190-02.

20. Pathak S, Multani AS, Narayan S. Anvirzel ${ }^{\mathrm{TM}}$, an extract of Nerium oleander, induces cell death in human but not murine cancer cells. Anticancer Drugs 2000;11:455-63.

21. Arai M, Stauber E, Shropshire CM. Evaluation of selected plants for their toxic effects in canaries. J Am Vet Med Assoc 1992;200:1329-31.

22. Szabuniewicz M, Schwartz WL, McCrady JD. Experimental oleander poisoning and treatment. Southwestern Vet 1972;25:105-14.

23. Szabuniewicz M, Schwartz WL, McCrady JD, Russell LH, Camp BJ. Treatment of experimentally induced oleander poisoning. Arch Int Pharmacodyn Ther 1971;189:12-21.
24. Hougen TJ, Lloyd BL, Smith TW. Effects of inotropic and arrhythmogenic digoxin doses and of digoxin-specific antibody on myocardial monovalent cation transport in the dog. Circ Res 1979;44:23-31.

25. Blum LM, Reiders F. Oleandrin distribution in a fatality from rectal and oral Nerium oleander extract administration. J Anal Toxicol 1983;11:219-21.

26. Haynes BE, Bessen HA, Wightman WD. Oleander tea: herbal draught of death. Annals Emergency Med 1985;14:350-3.

27. Eddleston M, Ariaratnam CA, Sjostrom L. Acute yellow oleander (Thevetia peruviana) poisoning: cardiac arrhythmias, electrolyte disturbances, and serum cardiac glycoside concentrations on presentation to hospital. Heart 2000;83:301-6.

28. Singh S, Shenoy S, Nehete PN, Yang P, Nehete B, Fontenot D, et al. Nerium oleander derived cardiac glycoside oleandrin is a novel inhibitor of HIV infectivity. Fitoterapia 2013;84:32-9.

29. ST, T. Research Int. An open-label, non-randomized, pilot study to test the safety and efficacy of Nerium-AS, a topical natural Nerium-based solution, (the Test Article) in patients with solar lentigines (Age Spots) and actinic keratosis. Report to Nerium Biotechnology, Inc; 2008.

30. ST, T. Research Int. Pharmacological effects of single and multiple dose topical administration of Nerium LS-A and Nerium LS-HW in New Zealand White Rabbits. Report to Nerium Biotechnology, Inc; 2009.

31. Fonseka MMD, Seneviratne SL, de Silva CE, Gunatilake SB, de Silva HJ. Yellow oleander poisoning in Sri Lanka: outcome in a secondary care hospital. Hum Exp Toxicol 2002;21:293-5. 